\title{
Thermal Energy Storage in a Confined Aquifer: Second Cycle
}

\author{
F. J. Molz, A. D. Parr, ANd P. F. ANDERsen \\ Civil Engineering Department, Auburn University, Auburn, Alabama 36849
}

\begin{abstract}
During the first 6-month injection-storage-recovery cycle of the Auburn University Aquifer Thermal Energy Storage Project, water pumped from an upper supply aquifer was heated to an average temperature of $55^{\circ} \mathrm{C}$ with an oil-fired boiler and then injected into a lower storage aquifer. Injection and recovery temperatures, flow rates, and temperatures at six depths in 10 observation wells and hydraulic heads in seven wells were recorded twice daily. The second-cycle injection, which was performed in a manner similar to the first, began on September 23,1978 , and continued until November 25, 1978, when 58,010 $\mathrm{m}^{3}$ of water had been pumped into the storage aquifer. The major problem experienced during the first cycle, a clogging injection well, was reduced by regular backwashing. This was done 8 times during injection and resulted in a $24 \%$ average injection rate increase compared to the first cycle. A 63-day storage period ended on January 27, 1979, and production of hot water began with an initial temperature of $54^{\circ} \mathrm{C}$. By March 23 this temperature had dropped to $33^{\circ} \mathrm{C}$, with $66,400 \mathrm{~m}^{3}$ of water and $76 \%$ of the injected thermal energy recovered. This compares to $66 \%$ recovery during the first cycle over the same drop in production temperature. Production of hot water continued until April 20, at which time $100,100 \mathrm{~m}^{3}$ of water and $89 \%$ of the injected thermal energy was recovered at a final production temperature of $27.5^{\circ} \mathrm{C}$. During the second cycle, measurements were made of relative land subsidence and rebound to a precision approaching $0.1 \mathrm{~mm}$. The surface elevation near the injection well rose $4 \mathrm{~mm}$ during injection, fell during storage, and fell more rapidly toward its original elevation during production. This movement was due to thermal expansion and contraction rather than to effects caused by head changes in the storage aquifer.
\end{abstract}

\section{INTRODUCTION}

Several studies aimed at determining the feasibility of using aquifers for the storage of thermal energy in the form of heated water have been reported recently [Mathey, 1977; Werner and Kley, 1977; Molz et al., 1978, 1979; Papadopulos and Larson, 1978]. Descriptions of additional studies which are presently underway or are being contemplated seriously may be found in the Proceedings of the Thermal Energy Storage in Aquifers Workshop [Lawrence Berkeley Laboratory, 1978] or in the survey paper by Tsang and Hopkins [1980], which also details the history of the aquifer storage concept on an international scale.

Although the city of Shanghai, China, has apparently had a relatively large aquifer storage program in operation for over a decade [Tsang and Hopkins, 1980], the largest experiment reported in the western literature was performed by Molz et al. [1979] near Mobile, Alabama. Beginning on March 18, 1978 , approximately $54,784 \mathrm{~m}^{3}$ of water were pumped from a shallow supply aquifer, heated to an average temperature of $55^{\circ} \mathrm{C}$, and injected into a deeper, confined aquifer where the ambient temperature was $20^{\circ} \mathrm{C}$. After a storage period of 51 days, $55,345 \mathrm{~m}^{3}$ of water were produced from the aquifer. During the 41-day production period the temperature of the produced water dropped from $55^{\circ} \mathrm{C}$ to $33^{\circ} \mathrm{C}$, and $66 \%$ of the injected thermal energy was recovered. This injection-storagerecovery cycle, which lasted approximately 6 months, was the first of a planned two-cycle experiment. The second cycle began on September 23, 1978, 18 days after the first cycle was terminated.

The major purpose of this communication is to describe the results obtained during the second injection-storage-recovery cycle. Specific objectives included: (1) measurement of the expected increase in energy recovery during the second cycle as

Copyright $(\odot) 1981$ by the American Geophysical Union. compared to the first, (2) measurement of land surface elevation changes due to aquifer storage at the Mobile site, (3) collection of hydraulic and temperature data for calibration of mathematical models used to simulate the transport processes associated with aquifer storage of thermal energy, and (4) further study of the clogging problem observed in the first cycle during injection. Computer simulations of both cycles were performed by the Lawrence Berkeley Laboratory and are reported in a related paper [Tsang et al., this issue].

\section{DESCRIPTION OF EXPERIMENT}

The project site is located in a soil borrow area at the Barry Steam Plant of the Alabama Power Company, about $20 \mathrm{mi}$ $(32 \mathrm{~km})$ north of Mobile, Alabama. Details concerning the location, well field geometry, and subsurface hydrology may be found in works by Molz et al. [1978, 1979]. A single well, located near the center of the observation well field, was used for both injection and production. Groundwater temperatures were recorded in 10 observation wells, and hydraulic heads were recorded in four observation wells, all located within the thermal radius of influence. Hydraulic heads alone were recorded in three additional wells located outside the thermal radius. The hydraulic data were recorded primarily for use in calibrating numerical models and will not be presented in detail herein.

The second injection-storage-recovery cycle was very similar to the first except the production continued for a longer period. Injection began on September 23, 1978, and continued until November 25, 1978, a total of 64 days. Shown in Figure 1 is the cumulative injection volume as a function of time. An injection rate varying from $845 \mathrm{~m}^{3} \mathrm{~d}^{-1}$ (155 gpm) to $1172 \mathrm{~m}^{3}$ $\mathrm{d}^{-1}(215 \mathrm{gpm})$ resulted in an injected volume of $58,010 \mathrm{~m}^{3}$ at an average temperature of $55^{\circ} \mathrm{C}$, as shown in Figure 2. A 63day storage period began on November 25,1978 , and was ter- 


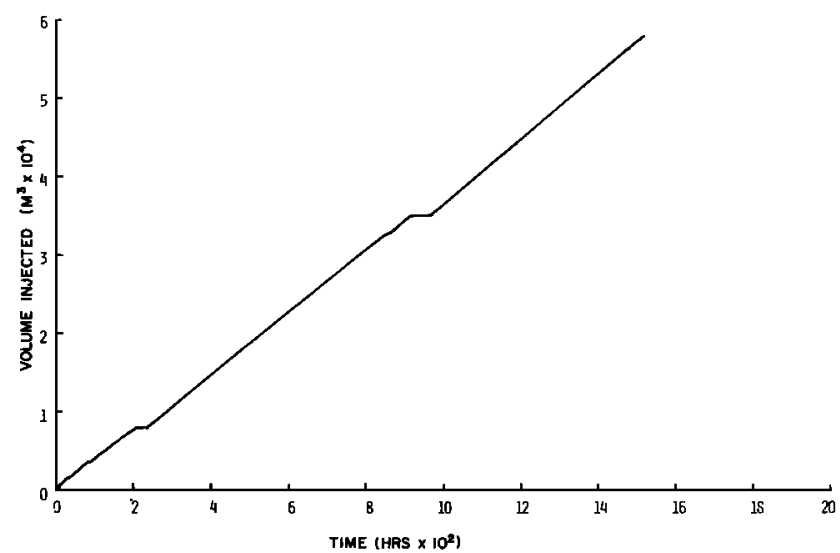

Fig. 1. Plot of cumulative injection volume as a function of time. The horizontal segments are due to pump shutdowns resulting from power failures and other problems.

minated on January 27,1979 , when production began and continued for approximately 84 additional days. As shown in Figure 3, the production pumping rate averaged $1205 \mathrm{~m}^{3} \mathrm{~d}^{-1}$ (221 gpm) and ultimately resulted in a production volume of $100,100 \mathrm{~m}^{3}$. Pumping was stopped when the production temperature reached $27.5^{\circ} \mathrm{C}$, which was $7.5^{\circ} \mathrm{C}$ above the ambient groundwater temperature.

At various times during the second cycle, careful level measurements were made in order to determine the magnitude of any surface elevation changes associated with aquifer thermal energy storage at the Mobile site. The locations of the four measurement stations are shown in Figure 4. Each station consisted of three surveying markers embedded in reinforced concrete. $A$ level was placed on the observation pad located approximately $30.5 \mathrm{~m}$ from the injection well. From this location, relative surface elevations of a point on pad $C$ and points on pads $B$ and $A$ were measured.

\section{RESULTS OF EXPERIMENT}

In the present communication and also in the work by Molz et al. [1979], relatively little discussion is devoted to the large amount of hydraulic and temperature data that were collected in the 14 observation wells. This material is discussed in some detail in a related paper [Tsang et al., this issue] along with the results of computer simulations of both injection-storage-recovery cycles. The temperature and head fields so generated can be viewed as a type of interpolation and contouring of the ac-

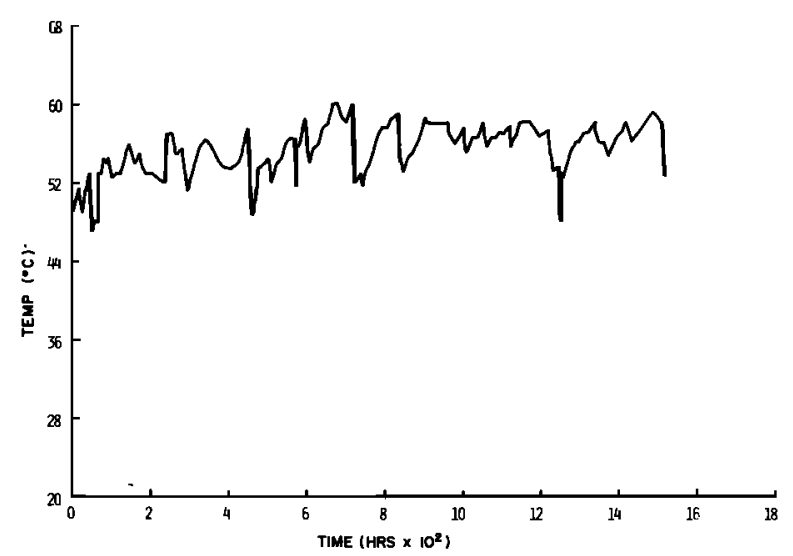

Fig. 2. Plot of injection temperature as a function of time.

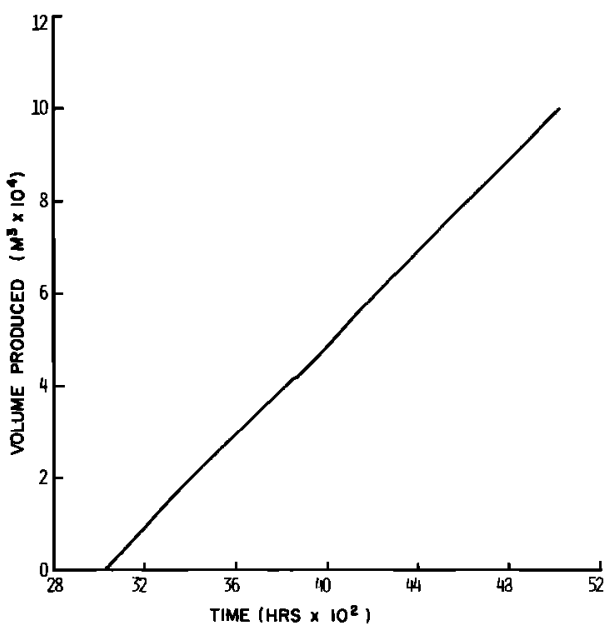

Fig. 3. Cumulative volume of water produced from the injectionproduction well as a function of time.

tual data points which allows a detailed 'picture' of the subsurface conditions to be developed.

Shown in Figure 5 is the temperature of the water pumped from the storage aquifer as a function of time. Because some of the energy injected during the first cycle was not recovered, the temperature of the produced water during second-cycle recovery dropped more slowly with respect to time than during the first cycle. This effect can be seen clearly in Figure 6, which is a plot of production temperature versus production volume for both the first and second cycles. Although secondcycle production temperature began at approximately $1^{\circ} \mathrm{C}$ below first cycle, temperatures became identical after a production volume of $4300 \mathrm{~m}^{3}$. Thereafter for a given production volume the second-cycle temperature was always higher than the first.

From the recorded temperature and flow rate of the injected water as functions of time one can calculate the amount of thermal energy injected above the ambient temperature. A similar calculation can be made for the amount of energy recovered. The equations actually used may be found in the work by Molz et al. [1979]. Shown in Figure 7 are plots of the thermal energy recovery factors as functions of recovery temperature. These factors are defined as the ratio of energy recovered at any time to the total energy injected. The increased energy recovery during the second cycle can be seen clearly. First-cycle recovery was terminated at a temperature of $33^{\circ} \mathrm{C}$ and a production volume of $55,300 \mathrm{~m}^{3}$. At this point, $66 \%$ of the injected energy had been recovered. During second-cycle recovery, $66,400 \mathrm{~m}^{3}$ of water had been produced, and $76 \%$ of the injected energy had been recovered when the production temperature reached $33^{\circ} \mathrm{C}$. When recovery was terminated at a temperature of $27.5^{\circ}$ and a production volume of 100,100 $\mathrm{m}^{3}, 89 \%$ of the injected thermal energy had been recovered.

Shown in Figure 8 are the elevation changes of pad $C$ with respect to reference pads $A$ and $B$. Ideally, pads $A$ and $B$ would have remained at the same relative elevation throughout the experiment, and the two elevation curves would be identical. However, there was a relative elevation change of approximately $1 \mathrm{~mm}$ between pads $A$ and $B$, largely during the latter two thirds of the experiment. This introduces an uncertainty into the actual elevation changes of pad $C$.

As soon as injection began, the land surface near the injec- 


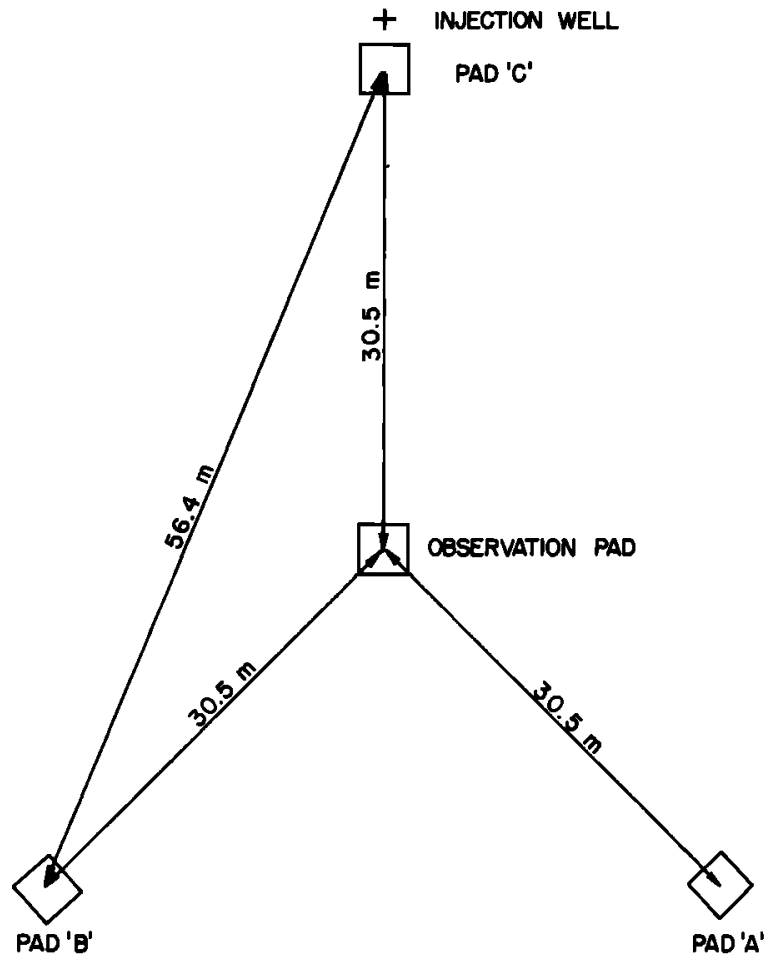

Fig. 4. Location of stations for measuring relative elevation changes of the land surface due to injection-production activities. Each pad measured 2.4 by 2.4 by $0.2 \mathrm{~m}$ and was composed of reinforced concrete. The pads were poured 3 weeks before measurements began.

tion well (pad C) started to rise with respect to both pads A and $B$. The rise continued at a decreasing rate until injection of hot water as terminated. During the storage period, pad C stopped rising and began to fall. After production pumping was initiated and throughout the production period, pad $C$ continued to drop toward the elevation of pad A. At the end of production, pad $C$ was located approximately 0 to $1 \mathrm{~mm}$ above its initial elevation.

\section{Discussion}

Molz et al. [1979] noted that the major technical problem encountered during the first cycle was clogging of the injec-

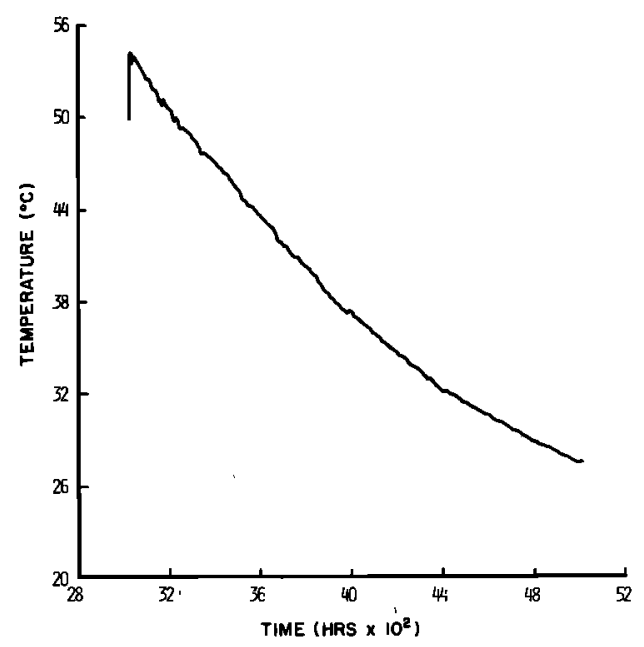

Fig. 5. Temperature of water pumped from the storage formation as a function of time.

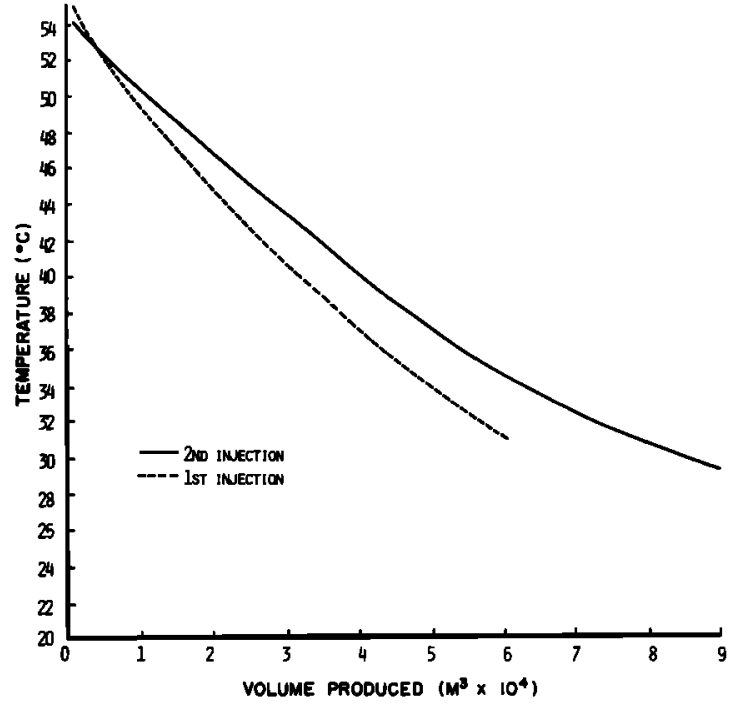

Fig. 6. Plots of production temperature versus production volume. The dashed line refers to the first cycle and the solid line to the second cycle.

tion-production well during injection. This problem persisted during second-cycle injection but was controlled to a greater extent by a regular well-backwashing program. Shown in Figure 9 is a plot of injection pressure versus time. Whenever the injection pressure at the wellhead reached approximately 1.45 $\times 10^{5} \mathrm{~N} \mathrm{~m}^{-2}$ (21 psi), water was pumped in and out of the injection well for short periods of time. After this procedure was completed, the injection pressure would drop, and the flow rate would increase. Shown in Figure 10 is the resulting specific capacity history of the injection well. Unlike the firstcycle injection, the average specific capacity between back-

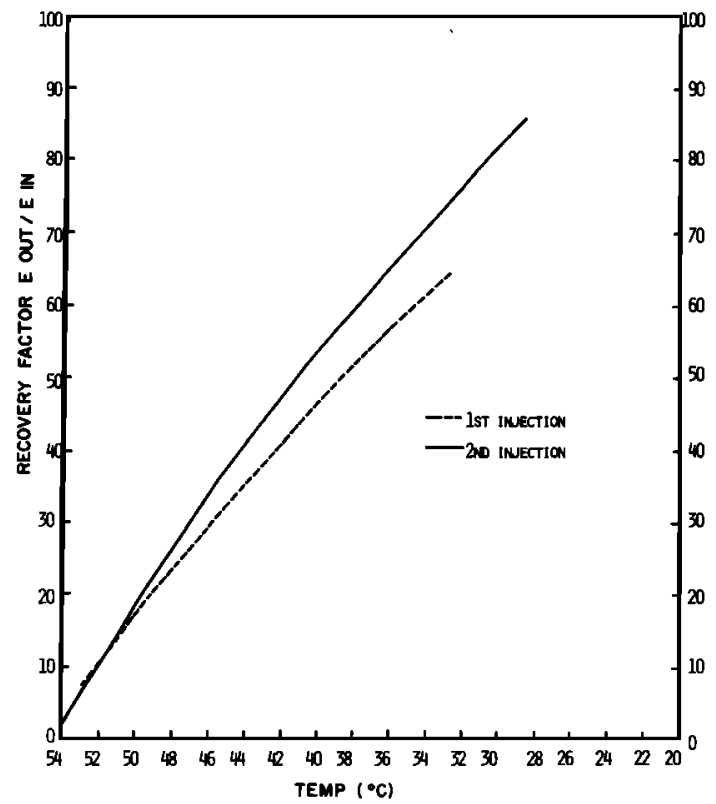

Fig. 7. Plots of the energy recovery factor, the ratio of energy recovered at any time during production to total energy injected, as a function of production temperature. The plots show that at the end of the first cycle, $66 \%$ of the injected thermal energy had been recovered. At the corresponding point of the second cycle, $76 \%$ of the energy had been recovered. 


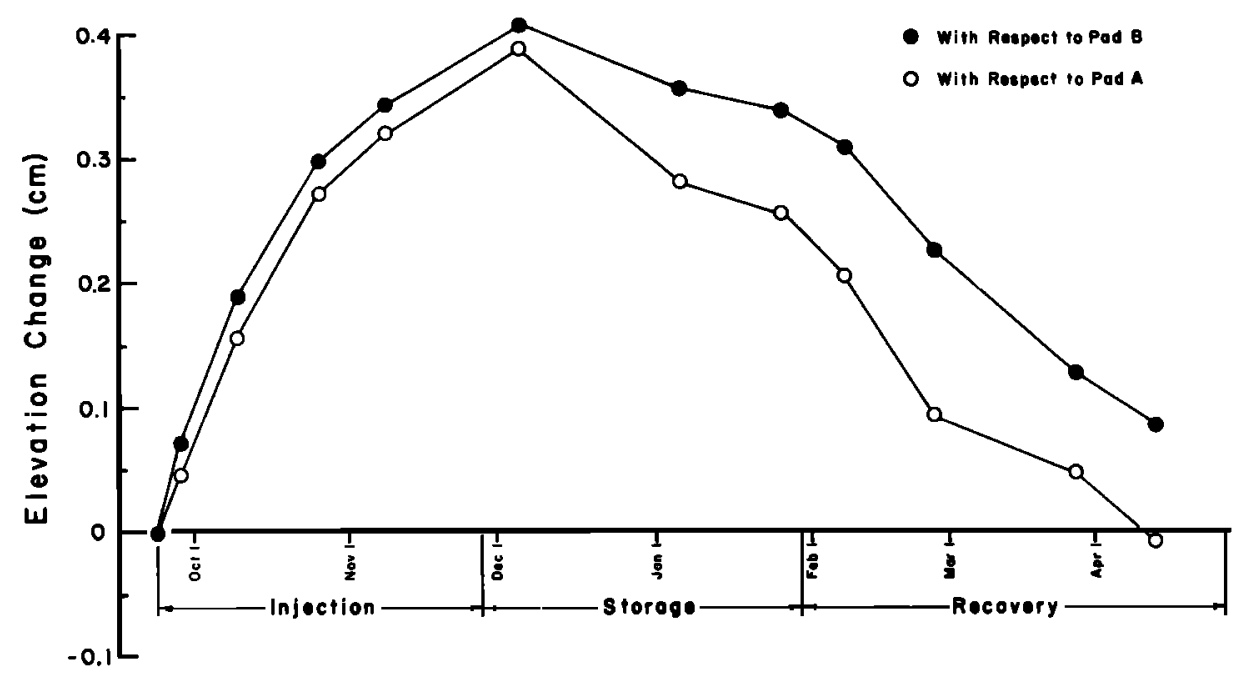

Time (Date)

Fig. 8. Relative elevation change of pad $C$ with respect to pads $A$ and $B$ as a function of time.

washings remained nearly constant with time, and the average injection rate was increased by $24 \%$.

Molz et al. [1979] estimated that during cycle 1 'a few 1000 lbs. [ $455 \mathrm{~kg}$ ] of clay material were removed during production pumping.' More careful and regular measurements during cycle 2 indicated an additional removal of $3500 \mathrm{~kg}$ of solid material, most of it clay. It is possible that the removal of clay materials during cycle 1 led to an increased permeability in the storage aquifer during cycle 2 . This is not likely, however, because the second-cycle recovery rate decreased by $18 \%$ under pumping conditions similar to cycle 1 . The observed removal of $3500 \mathrm{~kg}$ during cycle 2 production also lends more support to the theory that clay particle swelling, dispersion, and migration were the fundamental cause of the clogging problem observed in the Mobile experiments [Molz et al., 1979].

The rising and falling of the land surface in the vicinity of the injection well relative to the land surface $56.4 \mathrm{~m}$ away appeared to be due to thermal expansion and contraction rather than head changes in the storage aquifer and resulting flow into and out of aquitards. The main qualitative reason for this conclusion is that the rise was equal to or less than the fall. During injection, the excess pore pressure in the formation be-

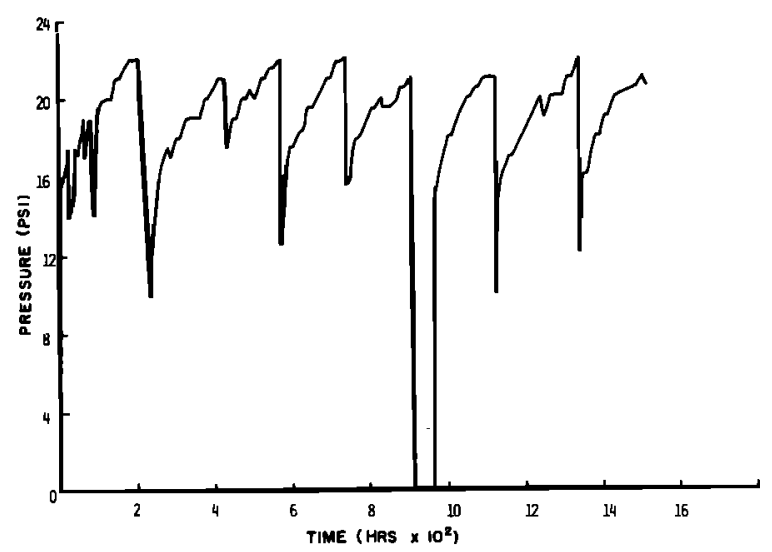

Fig. 9. Plot of second-cycle injection pressure as a function of time. The drops in pressure occurred right after backwashing operations. low pad C was approximately $3.45 \times 10^{4} \mathrm{~N} \mathrm{~m}^{-2}(5 \mathrm{psi})$ and during production was greater than this in a negative sense. If the observed effects were due to aquitard hydraulics, one would expect the consolidation to be larger than the expansion due to particle rearrangement during consolidation and the effect of the overburden weight. For the particular case in question one would expect expansion during injection, consolidation during storage, and considerably more consolidation during production, so that pad $C$ would end up well below its original elevation with respect to pad $A$. This type of behavior is common for the undisturbed, water-deposited clays found in the project area. That this pattern did not occur supports the thermal expansion and contraction hypothesis. Moreover,

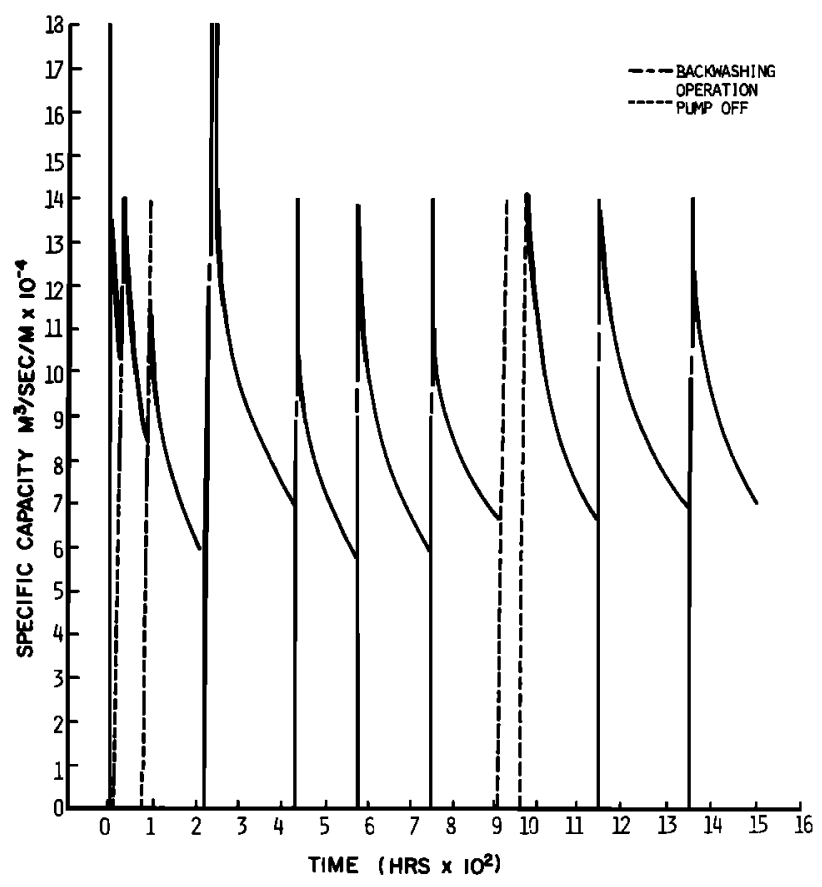

Fig. 10. Specific capacity of the injection well (second cycle) as a function of time. Between backwashing procedures the specific capacity decreased due to clogging of the formation around the injection well. 
a model study based on Terzaghi consolidation theory [ $\mathrm{Wu}$, 1966] indicated that pressure effects in the aquitards were many orders of magnitude below those required to raise the land surface $4 \mathrm{~mm}$ in 2 months.

Although the expansion and consolidation appear to be due to temperature changes, one cannot explain the results in terms of simple expansion and contraction of the storage aquifer matrix. If the temperature of the entire 22-m thickness of the storage aquifer were increased by $35^{\circ} \mathrm{C}$, one would expect an expansion of less than $\left(35^{\circ} \mathrm{C} \times 5.5 \times 10^{-7}{ }^{\circ} \mathrm{C}^{-1} \times 22\right.$ $\mathrm{m})=4.2 \times 10^{-4} \mathrm{~m}=0.42 \mathrm{~mm}$ if the matrix was composed of fused quartz grains. This number is approximately an order of magnitude less than the observed expansion. However, the expansion and contraction of water within the clay aquitards would be adequate to give the observed rise of approximately $4 \mathrm{~mm}$. The coefficient of thermal expansion of saturated clays in undrained conditions is of the order of $10^{-4}{ }^{\circ} \mathrm{C}^{-1}$ (approximately one-third the volume expansivity of water), which is 182 times greater than fused quartz. Thus the 4-mm rise could be due to heat flowing upward from the storage aquifer and, more importantly, outward from the well casing into the clay strata below observation pad C. Such effects are discussed in some detail by Campanella and Mitchell [1968]. Although the above argument is based on a coefficient of linear expansion for a fluid which cannot be defined uniquely, it is adequate in an order of magnitude sense to support the idea that heating clay strata can lead to relatively large initial changes in vertical thickness.

\section{SUMMARY AND CONCLUSIONS}

As predicted by theory [Lawrence Berkeley Laboratory, 1978], an increase in energy recovery was observed with multiple injection-storage-recovery cycles. At the Mobile site, second-cycle energy recovery was $76 \%$ in the temperature range from $55^{\circ} \mathrm{C}$ to $33^{\circ} \mathrm{C}$. Recovery at the end of the first cycle in the same temperature range was $66 \%$. The recovery was due mainly to injected energy remaining in the aquifer after the first cycle was completed.

Clogging of the injection-production well during injection posed less of a problem during the second cycle. A regular backwashing program was probably the main contributor to the observed $24 \%$ increase in average injection rate. Although the large quantity of clay pumped out of the storage aquifer during first-cycle production may have contributed to an increased permeability during second-cycle injection, there was no observed increase in the second-cycle production rate that could be attributed to this increased permeability. In fact, the production rate decreased by $18 \%$ during recovery. An additional $3500 \mathrm{~kg}$ of clay were removed during second-cycle production.

During injection, a concrete observation pad (pad C) near the injection-production well rose approximately $4 \mathrm{~mm}$ with respect to two reference pads located $56.4 \mathrm{~m}$ away. During storage, pad $\mathrm{C}$ stopped rising and began to fall. By the end of production, pad C was approximately 0 to $2 \mathrm{~mm}$ above its original elevation. It appears certain that the observed rise and fall was due to thermal expansion and contraction of water within clay strata near the hot well casing rather than head changes in the storage aquifer or thermal expansion and contraction of the storage aquifer matrix. Such temperature-induced rising and falling of the land surface should not pose an important problem in most situations.

The major problem identified by the Mobile experiments is clogging of the injection well. Such clogging can result from a myriad of geochemical and colloid chemical effects and is capable of completely halting an aquifer storage operation [Molz et al., 1979]. It is likely that storage of thermal energy in aquifers will be restricted severely until the clogging problem is better defined and techniques developed to prevent or control it.

Acknowledgments. This work was made possible through the financial support of the U.S. Department of Energy (contract 7338). The Alabama Power Company allowed us to conduct the experiment on their land and also maintained the roads leading to the site. This help is gratefully acknowledged. In addition, the writers would like to thank Rod Jenkins and Lance Bell, associate professors of Civil Engineering, Auburn University, for performing the land surface elevation measurements reported in this paper. Many fruitful discussions with Chin Fu Tsang and other members of the Lawrence Berkeley Laboratory are acknowledged also.

\section{REFERENCES}

Campanella, R. G., and J. K. Mitchell, Influence of temperature variations on soil behavior, J. Soil Mech. Found. Div. Am. Soc. Civ. Eng., 94, 709-734, 1968.

Lawrence-Berkeley Laboratory, Proceedings of the Thermal Energy Storage in Aquifers Workshop, edited by C. F. Tsang, Berkeley, Calif., 1978.

Mathey, F., Development and resorption of a thermal disturbance in a phreatic aquifer with natural convection, J. Hydrol., 34, 315-333, 1978.

Molz, F. J., J. C. Warman, and T. E. Jones, Aquifer storage of heated water, I, A field experiment, Ground Water, 16, 234-241, 1978.

Molz, F. J., A. D. Parr, P. F. Andersen, V. D. Lucido, and J. C. Warman, Thermal energy storage in a confined aquifer: Experimental results, Water Resour. Res., 15, 1509-1514, 1979.

Papadopulos, S. S., and S. P. Larson, Aquifer storage of heated water, II, Numerical simulation of field results, Ground Water, 16, 242 248, 1978.

Tsang, C. F., and D. Hopkins, Aquifer thermal energy storage: A survey, Spec. Pap. Geol. Soc. Am., in press, 1980.

Tsang, C. F., T. Buscheck, and C. Doughty, Aquifer thermal energy storage: A numerical simulation of Auburn University field experiments, Water Resour. Res., this issue.

Werner, D., and W. Kley, Problems of heat storage in aquifers, J. Hydrol., 34, 35-43, 1977.

Wu, T. H., Soil Mechanics, Allyn and Bacon, Boston, Mass., 1966.
(Received January 23, 1980; revised December 3, 1980; accepted December 10, 1980.) 